\title{
Hematologia de aves: Valores normais em hemograma de mutum de Alagoas (Mitu mitu)
}

\author{
Avian hematology: Normal hemogram values of Alagoas curassow \\ (Mitu mitu)
}

\author{
Nádia Regina Pereira Almosny, ${ }^{*}$ Kátia de Paula Silva, ${ }^{\star \star}$ Deise Lúcia da Silva Melo, ${ }^{\star \star \star}$ Thereza Christina de \\ Vasconcelos, ${ }^{\star \star \star *}$ Anderson de Oliveira Monteiro ${ }^{\star \star \star \star *}$
}

\begin{abstract}
Resumo
Para avaliação dos parâmetros normais no hemograma, foram coletadas amostras de sangue de sete exemplares de mutum de Alagoas, pertencentes à Zoobotânica Mário Nardelli. As técnicas utilizadas foram desenvolvidas no Laboratório de Patologia Clínica Veterinária da Universidade Federal Fluminense (RJ) e os parâmetros médios observados foram: volume globular: $35,7 \%$; hematimetria: $1.130 .000 / \mathrm{mm}^{3}$; hemoglobinometria: 11,4g/dl; volume globular médio (VGM): 315 $\mathrm{fl}$; concentração de hemoglobina globular média (CHbGM): $32 \%$; leucometria global: $7.850 / \mathrm{mm}^{3}$; basófilos: 0,4\%; eosinófilos 1\%; heterófilos: 10,8\%; linfócitos: $81,5 \%$; monócitos 1,5\%. Observou-se pequena variação dos animais estudados.
\end{abstract}

Palavras-chave: aves; Cracidae; hematologia.

\section{Introdução}

Atualmente, devido ao crescente interesse em relação à preservação de animais selvagens e entre eles, as aves, a avaliação hematológica tornou-se importante, pois o diagnóstico precoce da doença poderá ser decisivo em se tratando, às vezes, de um dos últimos exemplares da espécie, como é o caso do mutum de Alagoas (Nardelli, 1993).

As aves, assim como os répteis, anfíbios e peixes, possuem eritrócitos nucleados (Almosny et al., 1993d; Jenkins, 1995). São células grandes, se comparadas às de mamíferos e possuem vida média de trinta dias (Jenkins, 1995). Os leucócitos são, geralmente, semelhantes aos de mamíferos (Hankey \& Samour, 1988). Entretanto, observa-se a ausência de neutrófilos e a presença de um polimorfonuclear eosinofílico, porém com grânulos alongados, diferenciando dos eosinófilos que possuem grânulos redondos (Pereira et al., 1985. Jenkins (1995) relatou que, em corujas, este padrão se inverte.

Os heterófilos são pobres em proteases o que torna o pus das aves caseoso e não liqüefeito como nos mamíferos (Spano et al., 1987). Em coelhos também observa-se a presença de heterófilos (Pereira et al., 1985) sendo uma exceção entre os mamíferos.
Os trombócitos, ao contrário das plaquetas dos mamíferos que se originam do megacariócito, são oriundos de células mononucleares antecessoras, que têm um estágio de blastos como as demais células. Esta célula tem sido considerada como um eritrócito que não alcançou a maturidade. Entretanto, em alguns casos, ele poderá vir a sintetizar hemoglobina (Sturkye, 1968).

A contagem global de células necessita de método adequado, pois todas são nucleadas e não é possível a utilização de métodos adequados a mamíferos (Spano et al., 1987; Campbell, 1991; Almosny, 1993d).

Nardelli (1993) relatou que o número de espécies de aves que o mundo viu extingüir-se, somente no último século, aproxima-se de 100 (cem). Portanto, torna-se urgente a realização de estudos que possibilitem a preservação das espécies existentes. Os Cracídeos são aves que, se medidas não forem tomadas, em breve também acabarão. Dentre eles, o mutum de Alagoas é um dos mais raros.

Assim, o objetivo deste trabalho foi a descrição do hemograma em aves e a determinação de valores normais para mutum de Alagoas.

\footnotetext{
* Médico Veterinário, MsC, Prof. adjunto do Dep. de Patologia e Clínica Veterinária (UFF). Rua Cel. Moreira César 211/801 A, Icaraí - Niterói CEP 24230-052. Autor para correspondência.

** Médico Veterinário, Responsável pela Zoobotância Mário Nardelli.

*** Biólogo, Responsável pela Zoobotância Mário Nardelli.

${ }^{\star \star \star \star}$ Médićco Veterinário, MsC, Prof. responsável pela disciplina de Bioquímica da Faculdade de Veterinária Plínio Leite.

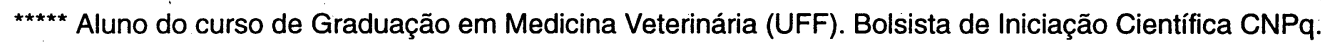




\section{Material e métodos}

Foram coletadas amostras de sangue de sete mutuns de Alagoas, através de punção de veia braquial. As amostras eram coletadas em frascos contendo ácido etilenodiaminotetracético $10 \%$ (EDTA) e esfregaços sangüíneos eram confeccionados no momento da colheita. O material era imediatamente acondicionado em isopor contendo gelo e enviado ao Laboratório de Patologia Clínica Veterinária da Universidade Federal Fluminense.

Por serem as hemácias das aves bastante sensiveis à hemólise, os hemogramas eram confeccionados logo que as amostras chegavam.

O volume globular era obtido pela técnica de microhematócrito e a hemoglobinometria pelo método de Drabkin utilizando-se de kit comercial tendo-se o cuidado de centrifugar o material diluído, para a precipitação do núcleo do material hemolisado.

A hematimetria e leucometria global foram obtidos em uma única diluição efetuada com soro fisiológico acrescido de corante Giemsa numa proporção de seis gotas para $10 \mathrm{ml}$ de diluente como descrito por Almosny et al. (1993d). Esta solução não é estável devendo ser efetuada no momento da confecção do exame.

A contagem foi efetuada em câmara de Newbauer, utilizando-se aumento de 400x, uma vez que era necessário diferenciar as células para contá-las.

Utilizou-se o retículo de hemácias para contagem de ambas as séries, sendo que, para leucócitos, foram contadas todas as células contidas em todos os 25 quadrados e multiplicouse o total pelo fator 1.000. Para contagem de eritrócitos utilizaram-se cinco quadrados e o fator de diluição foi 5.000 .

O volume globular médio e a concentração de hemoglobina globular média foram obtidas através das fórmulas:

$$
\begin{aligned}
& \overline{V G M}=\frac{V G(\text { Volume globular }) \times 100}{\text { hematimetria }} \\
& \mathrm{CHbGM}=\frac{\text { Hemoglobina } \times 100}{V G}
\end{aligned}
$$

Os esfregaços sangüíneos foram corados pelo método de May-Grunwald-Giemsa e a leucocitoscopia e a hematoscopia foram avaliadas em microscopia óptica utilizando-se aumento de 1000x.

Os corantes eram misturados numa proporção de uma parte de Giemsa para nove partes de May-Grunwald e seguia-se a coloração sobrepondo-se aos esfregaços, quinze gotas do corante. Após dois minutos, acrescentava-se vinte gotas de água destilada, homogeneizava-se e aguardava-se mais seis minutos. Os esfregaços eram então lavados em água corrente e colocados para secar para posteriormente serem analisados em microscopia óptica sm objetiva de imersão.

\section{Resultados e discussão}

Os valores obtidos no presente träbălho (Tabela 1) não revelam grande variação, observando-se que os valores máximos estiveram próximos. Relatos de Almosny (1993a, 1993b, 1993c) revelaram valores semelhantes em-outros Cracídeos. Devido ao pequeno número de exemplares da espécie, conforme descrito por Nardelli (1993), estas aves estão em vias de extinção e não existem muitos descritos de hemogramas das mesmas.

Tabela 1: Avaliação do volume globular, Hemoglobinometria, Hematimetria, Volume globular médio, Leucometria Global e Leucometria específica de sete mutuns do nordeste mantidos na Fundação Mário Nardelli (RJ).

\begin{tabular}{l|r|r|r|r|r|r|r|r}
\hline & 1 & 2 & 3 & 4 & 5 & 6 & 7 & $\mathrm{X}$ \\
\hline $\mathrm{Vg}$ & 34 & 40 & 36 & 38 & 32 & 33 & 37 & 35.7 \\
\hline $\mathrm{Hb}$ & 11 & 12.8 & 11.6 & 12.2 & 10.1 & 10.5 & 11.9 & 11.4 \\
\hline $\mathrm{H}^{*}$ & 1.1 & 1.3 & 1.1 & 1.2 & 1.0 & 1.0 & 1.2 & 11.3 \\
\hline $\mathrm{vgm}$ & 309 & 307 & 316 & 316 & 320 & 330 & 308 & 315 \\
\hline $\mathrm{chbgm}$ & 32.3 & 32 & 32.2 & 32.1 & 31.5 & 31.8 & 32.1 & 32 \\
\hline $\mathrm{Lg}^{*}$ & 8.0 & 9.0 & 8.0 & 6.0 & 9.0 & 8.0 & 7.0 & 7.85 \\
\hline $\mathrm{B}$ & 0 & 1 & 0 & 0 & 1 & 1 & 0 & 0.4 \\
\hline $\mathrm{E}$ & 0 & 1 & 2 & 0 & 2 & 1 & 1 & 1 \\
\hline $\mathrm{H}$ & 9 & 12 & 10 & 15 & 8 & 10 & 12 & 10.8 \\
\hline $\mathrm{L}$ & 90 & 84 & 72 & 81 & 92 & 80 & 72 & 81.5 \\
\hline $\mathrm{M}$ & 2 & 1 & 1 & 1 & 2 & 2 & 2 & 1.5 \\
\hline
\end{tabular}

O método mostrou-se eficiente para a contagem de células, não foram observadas alterações morfológicas e o corante utilizado delineou as membranas e corou suavemente os núcleos, o que possibilitou a diferenciação entre eritrócitos, leucócitos e trombócitos.

A metodologia proposta mostrou-se, prática, rápida e de baixo custo, além de eficiente.

Para a realização da leucometria específica não necessitou-se de coloração citoquímica pois os heterófilos e os eosinófilos de aves se diferenciam pela morfologia dos grânulos, conforme descrito por Spano et al. (1987); Campbell (1991); Almosny et al. (1993d) e Jenkins (1995).

Pereira et al. (1985), ao efetuar coloração citoquímica de "Sudan black" B em aves e coelhos, observaram que somente nestes últimos estas células eram de difícil diferenciação através da morfologia dos grânulos, através do MGG. 
No entanto, estes autores observaram que os eosinófilos desta espécie possuem maior número de grânulos e que estes eram maiores.

Observou-se uma predominância absoluta de linfócitos sobre os heterófilos, confirmando os estudos de Spano et al. (1987); Hawkey \& Samour (1988) e vasta literatura que revela maior número de linfócitos em aves onívoras. TrabaIhos de Almosny et al. (1992) e Jenkins (1995) revelam que os heterófilos são maiores em aves carnívoras e piscívoras.

Não se observaram diferenças entre os mononucleares (linfócitos e monócitos) de aves e as de mamíferos domésticos descrito por Jain (1993) e vasta literatura. Os basófilos possuem muitos grânulos, assemelhando-se aos de ruminantes.

Os eritrócitos apresentavam morfologia coerente com os relatos de Gonçalves (1987); Spano et al. (1987); Hawkey et al. (1988); e Jenkins (1995), sendo células nucleadas e algumas revelando leve policromasia.
A morfologia dos trombócitos variava de arredondada a ovalada, mas esta célula sempre apresentava o citoplasma hialino conforme relataram Almosny et al (1993d).

Não foram encontrados hemoparasitos no material examinado.

Maiores estudos deverão ser efetuados no sentido de caracterizar variações patológicas na espécie.

\section{Conclusões}

1 A contagem global de células foi bastante eficiente, utilizando-se a técnica descrita.

2 Não ocorreram variações dignas de nota entre os valores hematológicos das aves no presente estudo.

3 A coloração pelo método de MGG foi suficiente para a diferenciação entre as células, não tendo sido necessária a coloração citoquímica.

4 Estudos deverão ser efetuados para maiores conhecimentos sobre as variações decorrentes de estados patológicos.

\section{Abstract}

In order to determine normal hemogram values, blood samples were obtained from seven individuals of Alagoas curassow, from Zoobotânica Mário Nardelli. The used methods were developed at the Veterinary Clinical Pathology Laboratory at Universidade Federal Fluminense (RJ) and the mean values obtained) were: packed cell volume: $36,6 \% ;$ RBC: $1.200 .000 /$ $\mathrm{mm}^{3}$; hemoglobin: 11,8g/dl; mean corpuscular volume (MCV): $305 \mathrm{fl}$; mean corpuscular hemoglobin concentration (MCHC): 32,2\%; WBC: $8071 / \mathrm{mm}^{3}$; basophils: $0,9 \%$; eosinophils: 1,1\%; heterophils: $11,0 \%$; lymphocytes: $85,4 \%$; monocytes: $1,6 \%$. Little variation were observed between the sampled individuals.

Keywords: birds, Cracidae, hematology.

\section{Agradecimento}

Ao Sr. Pedro Nardelli, pelo seu importante trabalho no sentido de preservar espécies em extinção, pela gentileza em colocar seu plantel à disposição para trabalhos de pesquisa e pelo carinho com que nos recebeu.

\section{Referências bibliográficas}

ALMOSNY, N.R.P.; SILVA, K.P.; MELO, D.I.S. \& NASCIMENTO, M.D. Jacuguaçu (Penelope obscura): Valores Médios Observados em Hemograma. Anais do VI Congresso Internacional de Medicina Veterinária em Língua Portuguesa. Salvador - BA, 1993a.

ALMOSNY, N.R.P.; NASCIMENTO, M.D.; SILVA, K.P. \& MELO, D.I. S. O Mutum de Alagoas (Mitu mitu): Hemograma e Glicose sérica - Anais do VI Congresso Internacional de Medicina Veterinária em Língua Portuguesa. Salvador - BH, 1993b.

ALMOSNY, N.R.P.; SILVA, K.P.; MELO, D.I.S. \& NASCIMENTO, M.D. Estudo de Valores Normais do Hemograma dos Cracídeos: Mutum. Anais do VI Congresso Internacional de Medicina Veterinária em Língua Portuguesa. Salvador BA, 1993c.
ALMOSNY, N.R.P.; NASCIMENTO, M.D.; SILVA, K.P. \& MELO, D.I.S. hemograma de aves: Métodos - Anais do VI Congresso Internacional de Medicina Veterinária em Língua Portuguesa. Salvador - BA, 1993d.

ALMOSNY, N.R.P.; FEDULO, L.P.L.; VASCONCELOS, C.H.C.; RODRIGUES, R.R.; ROMÃO, M.A.P. - Avaliação do Hemograma de 9 (nove) Atobás (Sula leucogaster) do Litoral de Rio de Janeiro. XXII Congresso Brasileiro de Medicina Veterinária. Curitiba - PR, 1992.

CAMPBELL, T.W. Hematology of Exotic Animals. The Compendium Small Animal., v. 13, n. 6, p. 950-956, 1991.

GONÇALVES, I.P.D. Valores hematológicos de algumas espécie de aves mantidas em cativeiro. Arq. Fac. Vet. UFRGS, Porto Alegre, RS - v. 15/16, p. 89-94, 1987/88. 
HAWKEY, C.M., SAMOUR, H.J. The Valve of Clinical Hematology In Exotic Birds. In: JACOBSON, E.R., KOLLIAS, G.V. Exotic Animals. New York: Ghurghill Livingstone, 1988, p. 109-141.

JAIN,N.C. Essentials of Veterinary Hematology. Philadelphia : Lea \& Febiger. 1993.

JENKINS, J.L. Basic Avian Hematologic: Techniques of Collection, Preparation, and Identification. In: Exotic Animals - A Veterinary Handbook. New Jersey: Veterinary Learnine Sistems, 1995. p. 126-135.
NARDELLI, P.M. - A Preservação do Mutum de Alagoas (Mitu mitu). Rio de Janeiro : Semana llustrada Editorial, 1993. 251 p.

PEREIRA, N.R.; FAN, L.C.; NASCIMENTO, M.D.; ROSSI, M.I. Diferenciação dos Leucócitos de Galinhas e Coelhos pelo Método Citoquímico de Sudan Negro B. Anais do Congresso Estadual de Medicina Veterinária. Santa Maria - RS, p. 68, 1985.

SPANO, J.S.; PEDERSOLI, W.M.; KEMPPAINEN, R.J.; KRISTA, L.M., YOUNG, D.M. Baseline Hematologic, Endocrine and Clinical Chemistry Valves in Duckes an Roosters. Avian Diseases. v. 31, p. 800-803, 1987.

\section{JPINTOGOMÉRCIOEREDPREENTACÕES}

J. Pinto de Macedo - Livraria

- Especializada em Livros Técnicos Científicos (Nacionais e Estrangeiros)

- Equipamentos Médicos

- Materiais Cirúrgicos em Geral

- Laboratorial

- Medicamentos Veterinários

Rua Vital Brazil Filho, 64 - Parte

(Faculdade de Veterinária)

Niterói-RJ - Caixa Postal 126-048 CEP 24241-970 - Tel.: (021) 710-0229 